\title{
Selection of Diameter of Spherical Tagin Fracturing Process which Use Radio Frequency Identification Technology
}

\author{
Shengtong Yuan, Jian Chen \\ School of Mechatronic Engineering, Southwest Petroleum University, Chengdu 610500, China
}

\begin{abstract}
In recent years, multi-stage fracturing technology of horizontal well with intelligent sliding sleevebased on radio frequency identification technology is gradually applied to the field of horizontal well fracturing.The selection of diameter of spherical tag become a new problem because the new process need tags have slow speed when pass through the smart sleeve and these spherical tags could not come into being blocked by themselves when fracturing fluid backflow. This paper took some researches of diameter selection of the spherical tag through these two aspects. The numerical simulation and mechanics analysisresults show that, the smaller diameter of RFID tag, the higher recognition of signal within a certain range. However the diameter of RFID tag should not be too small considering the blocking in fracturing fluid backflow process.Spherical tag moving in the tubing which diameter is $76 m m$ carried by fracturing fluid, the diameter of spherical tag select $48 \mathrm{~mm}$ is suitable.
\end{abstract}

Keywords: Diameter selection; Spherical tag; Fracturing; RFID; Numerical simulation

\section{Introduction}

In order to improve recovery efficiency of low permeability oil reservoirs and shale gas reservoirs,the technologyofball injection slidingsleeve in horizontal well staged fracturinghavebeenwidelypromoted and applied ${ }^{[1]}$.The basic principle of horizontal multi-stage fracturing ${ }^{[2,3]}$ is dividing horizontal section into several segments using packer and sliding sleeveaccording to the needs of reservoir development,and open corresponding sliding sleevebythrowing balls with different size from small to big infracturing and acidizing processes, yet the fracturing series is limited as the hole size can't be large. Withtheproposalof the goalsforindustrial upgrading and optimization of resources exploitation, horizontal multi-stage fracturing graduallydevelops to a longer horizontal section, and the technology of ball injection slidingsleeve in horizontal well staged fracturing can't complete all the fracturing operationby place inpipe column at a time.

In recent years, multi-stage fracturing technology of horizontal well with intelligent sliding sleevebased on RFID

(Radio Frequency Identification) is gradually applied to the field of horizontal well fracturing. Different information codeare embedded into the RFID intelligence sliding sleeve and electronic tagsthrough computer, and form the only corresponding relations with each other, if a particular layer needs fracturing, then deliver the corresponding sphericalRFID tag, and when theRFID tagis pumped to the position of the intelligence sliding sleeve in that layer, the RFID communication unitobtains signal from RFID tag, the control command is outputted after communication units interpret it, then triggering the internal power plant, driving actuator moving, turning on oroff the sliding sleeve. identification technology, the diameter of spherical tagis uniform. So that smart sleevestaged fracturing tool based on RFID can improve the fracturing series ofhorizontalsection of a single well, and reducing the cost of the shale gas development in fracturing stage. The selection of diameter of spherical tag become a new problem because the new process need tags haveslow speed when pass through the smart sleeve and these spherical tags could not come into being blocked by themselves when fracturing fluid flow back. This paper took some researches of diameter selection of the spherical tag through these two aspects.

\section{Force Analysis of Spherical Tag carried by fracturing Fluid}

This section research the force of spherical tags with different diameterin fracturing fluidof horizontal sectionthroughCOMSOL software. Fluid force acting on moving object mainly includes viscous force, differential pressure acting force and wave-making resistance these three types.

The force of fracturing fluid carry the spherical tagin the horizontal section is mainly differential pressure acting force. In the movement process of the spherical tagin the horizontal section carried by fracturing fluid, the influence factors of the thrust on the spherical tagareviscositycoefficientofliquid, diameter ratio of thespherical tag and tubing, the fluid velocity and so on. But, comparing with viscositycoefficientofliquid, the diameter ratio of the spherical tag and tubing has a greater influence to the thrust; the fluid velocity is more affected by the pump rate of fracture fluid at well head. The following are force analyses of the spherical tagswith different diameter of $20 \mathrm{~mm}, 30 \mathrm{~mm}, 40 \mathrm{~mm}, 50 \mathrm{~mm}, 60 \mathrm{~mm}, 70 \mathrm{~mm}$ in the tubing which diameter is $76 \mathrm{~mm}$.

In fracturing process which useradio frequency 


\subsection{Numerical Simulation by COMSOL}

\section{(1) Flow channel model establish}

We analyzetheforces of spherical tagswith different diameter of $20 \mathrm{~mm}, 30 \mathrm{~mm}, 40 \mathrm{~mm}, 50 \mathrm{~mm}, 60 \mathrm{~mm}, 70 \mathrm{~mm}$ in the tubing which diameter is $76 \mathrm{~mm}$, the flow channel model corresponding to the tag with a diameter of $20 \mathrm{~mm}$, as shown in Figure 1. In horizontal sectionRFID tagand fluid have the same density, the tag is positionedin the center axis of the flow channel model.

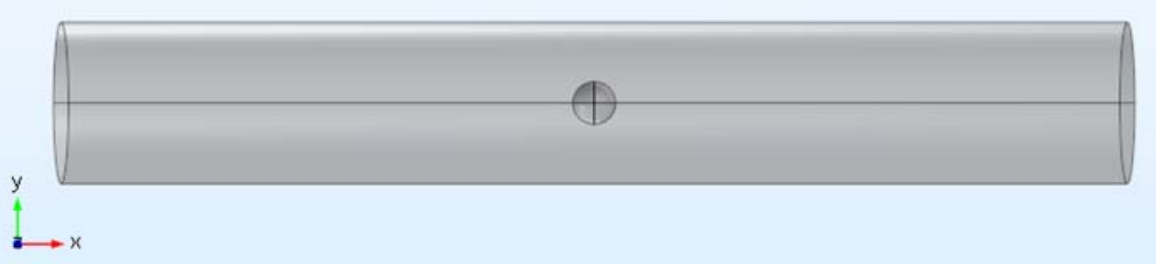

Figure 1: Flow channel model of numerical simulation

\section{(2) Physical field settings of numerical simulation}

In the simulation study, the density of fracturing fluid in horizontal section and RFID tag is set to $1000 \mathrm{Kg} / \mathrm{m}^{3}$, the viscosity coefficients of fluid is set to $100 \mathrm{mPa} / \mathrm{s}$.

Fluid Simulation Analysis Inlet boundary conditions are defined as fluid flow conditions at the inlet. Commonly used fluid flow inlet boundary conditions in COMSOL are velocity inlet conditions, pressure inlet conditions, and mass flow inlet conditions ${ }^{[4-6]}$. The velocity inlet boundary conditions can be adopted by this numerical simulation. The velocity is set to $1.838 \mathrm{~m} / \mathrm{s}$.

Those Common boundary conditions for fluid flow in COMSOL are velocity outlet conditions, pressure outlet conditions, and open boundaries ${ }^{[7-9]}$. The boundary conditions of the pressure outlet are selected by incorporating the field fracturing process, and the pressure is set as the fracturing pit bottom pressure: $80 \mathrm{MPa}$.

\section{(3) Meshing}

Combining the resultofgrid independence validation, the accuracy and time cost, it's better to choose the number of grid in the flow field model at around 240,000. Mesh subdivision is applied to spherical tag.

\section{(4) Calculation and post-processing}

COMSOL result processing can be used to swiftly solve the mathematicproblems bydoing integral, averaging, calculatingextreme value and so on towardthe results from selected domain, surface, line, and point. It also contains the post-processing function of "the accurate integral about reaction force and flow", which is expressed by "reacf ()". Through the method of "sum up the nodes" in surface integral to solve the "reacf ()" can calculate the reaction force and reaction flow in the selected face. In the fluid flow, the reaction force of the fluid towards the target surface can also be solved by "reacf ()", in the whole solution -reacf (u), - reacf $(v)$, - reacf $(\mathrm{w})$ are respectively presenting the reaction force of the fluid towards the target surface from $X$, $\mathrm{Y}, \mathrm{Z}$ directions.

After the modeling, physical field setting, meshing, solver setting, and calculation,we can getthe stress of static tag in $\mathrm{x}$ direction by solving $-\operatorname{reacf}(u)$.

\subsection{Force analyses of spherical tags with different diameters}

The thrust on spherical tags with different diameters can be obtained by COMSOL, the nephogram of force is shown in Figure 2.The data of "-reacf(u)" which are resultant force in the $\mathrm{x}$ directionare shown in table 1 .

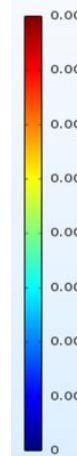

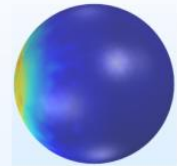

$d=20$

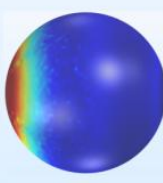

$\mathrm{d}=50$

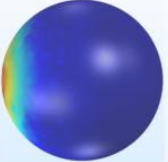

$\mathrm{d}=30$

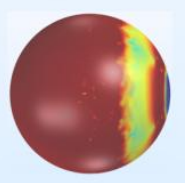

$\mathrm{d}=60$

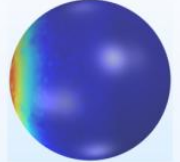

$\mathrm{d}=40$

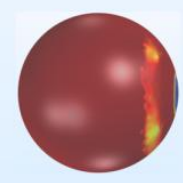

$\mathrm{d}=70$
Figure 2: Nephogram of thrust on spherical tags with different diameters in $76 \mathrm{~mm}$ tubing

Table 1: Resultant force in the $\mathrm{x}$ direction of spherical tags with different diameters

\begin{tabular}{|c|c|c|c|c|c|c|}
\hline Diameter ( $\mathrm{mm})$ & 20 & 30 & 40 & 50 & 60 & 70 \\
\hline $\begin{array}{c}\text { Resultant force in the } \\
\mathrm{x} \text { direction }(\mathrm{N})\end{array}$ & 0.101 & 0.363 & 0.885 & 1.804 & 10.269 & 58.377 \\
\hline
\end{tabular}

From table 1, the axial force on spherical tagwithdifferent size is different, which increases along with the increasing of diameter of tag and increases rapidly as the diameter of tag is approaching the diameter of tubing.

In multi stage fracturing technology of horizontal well based on RFID, the larger velocity of RFID tag when passing by sliding sleeve will lead to the lower signal recognition raised in the research background of this paper. So in a certain range, the diameter of tag is smaller, the less thrust, the better signal recognition.

\section{Volume 6 Issue 1, January 2017 www.ijsr.net}




\section{International Journal of Science and Research (IJSR) \\ ISSN (Online): 2319-7064 \\ Index Copernicus Value (2015): 78.96 | Impact Factor (2015): 6.391}

\section{Study of Blocked Tag when Fluid Flowback}

\subsection{Mechanics analysis for blocked tag}

Fracturing fluid flowback is an important part of hydraulic fracturing technique, proper velocity of flowback is one important factor toincrease oil output. But the situation that tag beenblocked with each other appear at the scene of flowback, which results from thattag pushing against each other make the thrust on tag applied by fracturing fluid less than the friction between tag and the wall of tubing. The forces on twoblocked tags in static state are shown as Figure 3.
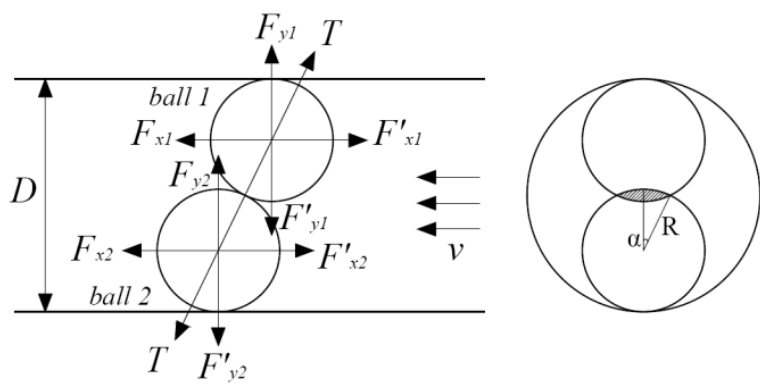

Figure 3 Free-body diagram of two blocking spherical tags

The component forces applied to two tagsare expressed as equation (1) and equation(2) respectively.

$$
\left.\begin{array}{l}
F_{x 1}=F_{w 1} \\
F_{x 1}^{\prime}=T \sin \alpha+f=T \sin \alpha+\mu N \\
F_{y 1}=F_{F}+T \cos \alpha \\
F_{y 1}^{\prime}=G+N \\
F_{x 2}=F_{w 2}+T \sin \alpha \\
F_{x 2}^{\prime}=f=\mu N \\
F_{y 2}=F_{F}+N \\
F_{y 1}^{\prime}=G+T \cos \alpha
\end{array}\right\}
$$

$F_{w 1}, F_{w 2}$ - - the axial thruston tag 1 and 2 from fracturing fluid;

$f$ - the friction between tag and wall of tubing, $f=\mu N, \mu$ represents frictioncoefficient, $N$ represents the pressure applyto tag ball from wall.

$F_{F}$ — - buoyancyapply to tag from fracturing fluid.

$G$ - - the gravity of tag ball.

See tag 1 and 2 asa system, the force along the axis direction have following balance:

$$
F_{w 1}+F_{w 2}=2 \mu T \cos \alpha
$$

Connect equation (1), (2), (3), simplified as:

$$
F_{w 2}=F_{w 1} \frac{\mu \cos \alpha-\sin \alpha}{\mu \cos \alpha+\sin \alpha}
$$

According to the description of differential pressure force and the formula of air drag showing as $f=\frac{1}{2} C \rho S v^{2}$, we can think that the thrustapply to tag from fracturing fluid and the frontal area of tag towards liquid is proportional, that is:

$$
F_{w} \propto S
$$

The following equation (6) can be obtainedfrom figure 3 :

$$
\frac{S_{b 1}}{S_{b 2}}=\frac{S_{R}}{S_{R}-S_{s}}=\frac{\pi R^{2}}{\pi R^{2}-4 \pi R^{2} \frac{\alpha}{2 \pi}+2 R^{2} \sin \alpha \cos \alpha}
$$

$S_{b 1}, S_{b 2}$ — the frontal area toward liquidof tag 1 and tag 2 ;

$S_{R}$ — projection areaof tag ball;

$S_{S}$ — - the shaded area of figure 3 .

Connect equation (4), (5), (6), simplified as:

$$
\pi-2 \alpha+2 \sin \alpha \cos \alpha=\pi \frac{\mu \cos \alpha-\sin \alpha}{\mu \cos \alpha+\sin \alpha}
$$

The following equation can be obtainedfromthe tangential relationship of two tags in figure 3:

$$
\frac{4 R-D}{2}=R-R \sin \alpha
$$

Simplified as:

$$
\sin \alpha=\frac{D}{2 R}-1, \frac{D}{4} \leq R \leq \frac{D}{2}
$$

In conclusion, study the migration of RFID tag carried by fracturingfluid in tubing with a diameter of $76 \mathrm{~mm}$, the extremum of radius of tag has the follow relationship for avoidingtag been blocked with each other in the process of fracturing fluid backflow:

$$
\left.\begin{array}{r}
\pi-2 \alpha+2 \sin \alpha \cos \alpha=\pi \frac{\mu \cos \alpha-\sin \alpha}{\mu \cos \alpha+\sin \alpha} \\
\sin \alpha=\frac{38}{R}-1
\end{array}\right\}
$$

$(19 \leq R \leq 38)$

\subsection{Equation Solution and analysis}

Equation (9) in section 2.1 is a nonlinear equation, the numeric calculation can be obtainedby newton iterative method, the solving codeswrite in MATLABare showing as following (the friction coefficient was set as 0.1 considering the action of mud and fracturingfluid,thepacking material for RFID tag is syntheticresin):

\%implicit function - show

clear

syms u r\%variable

$\mathrm{yf}=3.1415 * \mathrm{u}^{*} \operatorname{sqrt}\left(76 / \mathrm{r}-144 / \mathrm{r}^{\wedge} 2\right)+3.1415 *(38 / \mathrm{r}-1)-2 * \mathrm{u}^{*} \operatorname{sqrt}(76$ $\left./ \mathrm{r}-144 / \mathrm{r}^{\wedge} 2\right)+2 * \operatorname{asin}(38 / \mathrm{r}-1) *(38 / \mathrm{r}-1)+\mathrm{u}^{*}(38 / \mathrm{r}-1) * \operatorname{sqrt}\left(76 / \mathrm{r}-144 / \mathrm{r}^{\wedge} 2\right)$

${ }^{\wedge} 2+(38 / \mathrm{r}-1)^{\wedge} 2 * \operatorname{sqrt}\left(76 / \mathrm{r}-144 / \mathrm{r}^{\wedge} 2\right)-3.1415 * \operatorname{sqrt}\left(76 / \mathrm{r}-144 / \mathrm{r}^{\wedge} 2\right)+3.141$ $5 *(38 / \mathrm{r}-1)$

$\mathrm{ut}=0.1 ; \%$ friction coefficient

$\mathrm{f}=\operatorname{subs}(\mathrm{yf}, \mathrm{u}, \mathrm{ut})$;

$\mathrm{r} 0=23$; \% the estimated initial value for solving numerical solution 


\section{International Journal of Science and Research (IJSR) \\ ISSN (Online): 2319-7064}

Index Copernicus Value (2015): 78.96 | Impact Factor (2015): 6.391

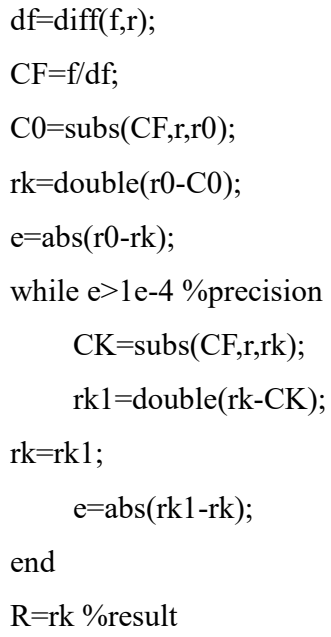

The calculation result is 23.9465 , so blockage can appeared when the radius of spherical tag is around $24 \mathrm{~mm}$. The radius magnitude, $23.9465 \mathrm{~mm}$, is only one extremum. The suitable range oftag diameter should be $19 \leq R \leq 23.9$ or $24.0 \leq R \leq 38$ that could prevent blockingis discussing in the following:

By force analysis in figure 3 we can learn that, with the radius $\mathrm{R}$ reduced, $\sin \alpha$ reduced, $\cos \alpha$ increased,the $\mathrm{y}$ components of $F_{w 1}$ to tag2 increased, the pressure on the wall of the tubing by tag ball 2 increased. When the velocity of backflow fluid is small, that is the influence on $F_{w 2}$ of the change of the frontal area toward liquid of tag 2 is small, obviously the following relationship will appear:

$$
F_{w 2}+T \sin \alpha<f=\mu\left(G+T \cos \alpha-F_{F}\right)
$$

Hence the blocksituation occurs.

All above analysis ofblockage is aimed at two spherical tags, that is the researchedradius of tag is $\frac{D}{4} \leq R \leq \frac{D}{2}$.

When the radius of tag ball is less than a quarter of pipe diameter, the situation that two tagsblocked with each other can't occur, but in theory the configurationshown as Figure 4 is always occur(only three balls is shown, the rest is similar)
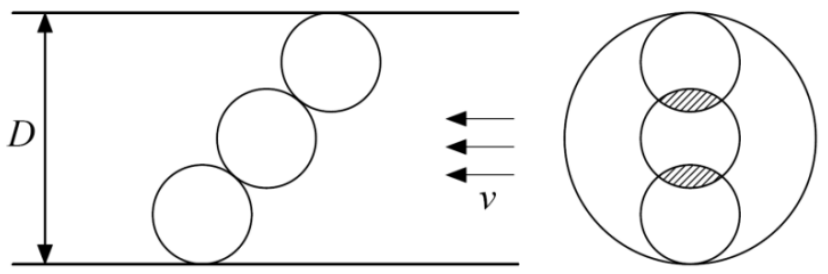

Figure 4: Schematic diagram of three blocking spherical tags

For the smaller diameter, the thrust on tagfrom fluid is small verified by the simulation analysis above. The configuration of tags is shown as Figure 4, the radial force between spherical tags lead to the fact that the friction resistance is larger than the thrust, resulting in the blocking.Concrete mechanical analysis and solution issimilar with the analysis of two tagsresearched above.

In conclusion, the diameter of spherical tag selected as $48 \mathrm{~mm}$ is properfor tubing which diameter is $76 \mathrm{~mm}$ based on the research of reducing the speed of spherical tag when pass through the smart sleeve and preventing the tags blocked with each other.

\section{Conclusion}

Smart sleeve staged fracturing tool based on RFID was used in oil formation improvement for reduce fracturing cost.This paper takes the research of diameter selection of spherical tag according to the problem of the lower signal recognition and the backflow blocking. We can get following conclusion:

The larger velocity of spherical tag when passing by sliding sleeve will lead to the lower signal recognitionrose in the research background of this paperbased on RFID multi stage fracturing technology of horizontal well. Therefore the smaller diameter of RFID tag, the smaller the thrust, the higherrecognition of signal within a certain range.

The smaller diameter of spherical tag will lead to blocking in the fracturing fluid backflow process, and the diameter of RFID tag designed for fracturingcan optimize with the formula this paper suggested. Through the analysis ofspherical tag moving carried by fracturing fluid in the tubing which diameter is $76 \mathrm{~mm}$, the diameter of sphericaltag select $48 \mathrm{~mm}$ is suitable.

\section{Acknowledgments}

This work reported in this paper was supported by the Seeding Program for Technological Innovation of the Science and Technology Department of Sichuan Province (2016128)

\section{References}

[1] Cai X, Tang H, Zhou K. Pattern optimization of hydraulically fractured horizontal wells in low permeability and thin interbeddedreservoirs[J]. SPECIAL OIL \& GAS RESERVOIRS. 2010, 4(17): $72-74$.

[2] Lohoefer D S, Seale R A, Athans J. New Barnett Shale Horizontal Completion Lowers Cost and Improves Efficiency[J]. SPE 103046. 2006.

[3] Li S. Research on Technology of Sliding Sleeve Ball Injection Diverter Pipe String in Horizontal Wells[J]. PETROLEUM GEOLOGY \& OILFIELD DEVELOPMENT IN DAQING. 2005, 24(4): 67-69.

[4] Qian X, Deng Y, Liu Y. An Explicit Boundary Level Set Method for Optimization Design of Fluid Channel[J]. China Mechanical Engineering. 2013, 24(15): 2097-2100. 


\section{International Journal of Science and Research (IJSR) \\ ISSN (Online): 2319-7064}

Index Copernicus Value (2015): 78.96 | Impact Factor (2015): 6.391

[5] Li D, Xu C, Xiong Z. Gas flowing model of mining face and solve it using COMSOL[J]. JOURNAL OF CHINA COAL SOCIETY. 2012, 37(6): 967-971.

[6] Salvi D, Boldor D, Aita G M. COMSOL Multiphysics model for continuous flow microwave heating of liquids[J]. JOURNAL OF FOOD ENGINEERING. 2011, 104(3): 422-429.

[7] Chen D. Multi-physical field coupling simulation of hygro-thermal deformation of concrete[J]. JOURNAL OF SOUTHEAST UNIVERSITY. 2013, 43(3): 582-587.

[8] Xu Y, Xu Q. Finite element analysis of seepage based on COMSOL Multiphysics[J]. Engineering Journal of Wuhan University. 2014, 47(2): 165-170.

[9] Rushd S, Saanders R. APPLICATION OF A CAPACITANCE SENSOR FOR MONITORING WATER LUBRICATED PIPELINE FLOWS[J]. CANADIAN JOURNAL OF CHEMICAL ENGINEERING. 2014, 92(9): 1643-1650. 